\title{
Jak myślą prorocy? O procesie zachodzącym w ludzkim umyśle podczas prorokowania*
}

\section{How do the prophets think? On the process of the human mind while prophesying}

Streszczenie. Fenomen proroctwa w interpretacji o. José María Arévalo jest procesem współpracy Bożej łaski objawiającej nam prawdę o samym Stwórcy i ludzkiego intelektu, który swymi naturalnymi siłami i zgodą na działanie jest w stanie przyjąć wiedzę o tym, co nadprzyrodzone. Kolumbijski autor ukazuje nam w ten sposób nauczanie Tomasza z Akwinu o proroctwie jako coś, co w interesujący sposób wpisuje się w znane ujęcie Akwinaty odnoszące się do relacji między łaską i naturą: gratia non tollit naturam sed perficit. Jest to bardzo aktualny i potrzebny przekaz $\mathrm{w}$ dobie postmodernistycznego kryzysu ludzkiej racjonalności i wiary.

\begin{abstract}
The phenomenon of prophecy, as interpreted by Fr. José María Arévalo, is a process of cooperation of God's grace revealing to us the truth about the Creator himself and the human intellect, which using its natural powers and consent to act is able to accept the knowledge of the supernatural. This is how the Colombian author presents the teaching of Thomas Aquinas on prophecy. He treats it as something inscribed in an intriguing manner in Aquinas' well-known approach to the relationship between grace and nature: gratia non tollit naturam sed perficit. It is a timely and much-needed message in the era of postmodern crisis of human rationality and faith.
\end{abstract}

Słowa klucze: Tomasz z Akwinu; proroctwo; proces poznawczy; proces intelektualny.

Keywords: Thomas Aquinas; prophecy; cognitive process; intellectual process.

* Recencja książki J.M. Arévalo, El proceso intelectual de la profecía según Santo Tomás, Universidad Santo Tomás, Bogota 2020, ss. 175. 
W wydanej w roku 2020 książce José María Arévalo próbuje przeanalizować pracę ludzkiego intelektu napotykającego rzeczywistość, która go przerasta, bo pochodzi z ponadnaturalnego Objawienia Bożych tajemnic. Jak w związku z tym funkcjonuje i zachowuje się ludzki umysł? Jaka jest i czy w ogóle jest jego rola w przyjęciu i przekazaniu treści, które pochodzą wprost od Boga? Czy proroctwo, o którym tu mowa, domaga się czy wyklucza pracę ludzkiego myślenia? Na te pytania próbował odpowiedzieć kolumbijski autor już przed laty, broniąc swej tezy na Angelicum w Rzymie w latach 70, a co teraz staraniem wydawnictwa Uniwersytetu Świętego Tomasza z Bogoty zostało udostępnione szerszemu gronu czytelników.

Sam temat jest cały czas bardzo aktualny, bo traktujący o kwestiach współpracy ludzkiej natury z łaską działającego Boga. Całościowa analiza epistemologiczna pracy ludzkiego intelektu w procesie prorokowania oparta została przez dominikanina nie tylko o teksty biblijne i nauczanie Tomasza z Akwinu o charyzmacie prorockim, ale także o Jego prace dotyczące kwestii ludzkiego poznania pozwala uchwycić to, co często umyka postawom czysto fideistycznym negującym wagę czy potrzebę działania ludzkiego czynnika w recepcji Bożej łaski, czy, z drugiej strony, głosom post oświeceniowego racjonalizmu, negującym w ogóle możliwość istnienia innych źródeł ludzkiego poznania niż stricte naturalne, czy wręcz naturalistyczne. Nie dziwi więc wielka aktualność tematu wtedy, gdy José María Arévalo pisał i bronił swej tezy, a więc w czasach bardzo żywej teologicznej dyskusji pomiędzy prądami modernistycznymi i tymi, którzy próbowali bronić i rozwijać tradycyjne dotychczasowe kierunki interpretacji zjawiska poznania tego, co nadprzyrodzone. Ale i dzisiaj temat pozostaje bardzo ważny, gdy w ramach kryzysu ludzkiej racjonalności doby postmodernizmu pojawiają się w duchowości czy w filozofii a nawet w teologii, różne tendencje do podążania za transhumanistycznymi i pozaracjonalnymi metodami działania ludzkiego poznania $^{1}$. Stad dużym plusem wydania pracy pochodzącej $z$ lat 70 . ubiegłego wieku jest dodanie doń współczesnego komentarza autorstwa Germána Correa Miranda pokazującego nam myślowe uwarunkowania epoki, w której powstawała praca o proroctwie i współczesną dyskusję dotyczącą kwestii poruszanych

1 Por. A. Marcos, M. Perez, Caverna 2.0. Las raíces dualistas del transhumanismo, Scientia et Fides 2 (2019), s. 23-40 (DOI: http://dx.doi.org/10.12775/SetF.2019.014); J. Merlo, Zarathustra and Transhumanism: Man is Something to Be Overcome, Scientia et Fides, 2 (2019), s. 41-61 (DOI: http://dx.doi.org/10.12775/SetF.2019.01). 
przez Arévalo ${ }^{2}$. W ten sposób zapoznać się możemy ze współczesną literaturą przedmiotu i zaktualizować ważny głos pochodzący z ubiegłego stulecia.

Powracając do kwestii źródeł głównego omawianego dzieła, kolumbijski autor sięga więc oczywiście po fragmenty De Veritate ${ }^{3}$ i Sumy teologicznej ${ }^{4}$, które nazywane są wprost Traktatami o proroctwie czy po komentarze biblijne Akwinaty, takie jak na przykład te do Listów św. Pawła ${ }^{5}$ czy do Księgi Izajasza ${ }^{6}$, ale też są przywoływane inne, nieprorockie kwestie pochodzące z Summa theologiae ${ }^{7}$ czy z De Veritate $^{8}$ czy fragmenty innych dzieł, w tym komentarzy do Arystotelesa ${ }^{9}$, w których średniowieczny autor rozważa kwestie epistemologiczne. Nie brak także odniesień do dzieł samego Stagiryty dotyczących gnozeologii. Sięgnięcie po drugi rodzaj źródeł pozwoliło dominikaninowi przeanalizować dogłębnie pracę ludzkiego umysłu spotykającego na swej drodze coś, co pochodzi od samego Boga, a co zawarte jest w prorockich tekstach Pisma Świętego ${ }^{10}$.

Autor przeprowadza dokładną analizę poszczególnych etapów myślenia człowieka, który doświadcza natchnienia prorockiego. Wyróżnione, już na poziomie głównych rozdziałów książki, konkretne części procesu intelektualnego mającego miejsce w umyśle proroka, są wyraźnie oparte o ogólną teorię poznania ludzkiego zawartą w doktrynie Tomasza z Akwinu. To, jak i podkreślenie końcowego efektu pracy ludzkiego intelektu w postaci podjętego prawdziwego sądu o „pomyślanych” z pomocą Bożą rzeczywistościach podkreśla dobrze integralny charakter pracy umysłu proroka. Ma to wielkie znaczenie przy ukazywaniu konieczności ludzkiego współdziałania w przekazywaniu przez Boga konkretnych

2 Por. G. Correa Miranda, Liminar. Los juicios de Dios en la mente de un profeta, w: J.M. Arévalo, op. cit., s. 15-88.

3 Por. De veritate, q. 12.

4 Por. S. Th., II-II, qq. 171-174.

5 In omnes S. Pauli apostoli Epistolas commentaria, Turyn 1929.

6 In Isaiam prophetam expositio, Paryż 1876.

7 Por. np. J.M. Arévalo, op. cit., s. 124 i 126 - S. Th., I, q. 16, a. 2.

8 Por. np. J.M. Arévalo, op. cit., s. 123-125 - De veritate, q. 1, a. 3 I a. 9.

9 Por. np. Sententia libri De anima.

10 Por. P. Roszak, Exégesis y metafísica. En torno a la hermenéutica bíblica de Tomás de Aquino, Salmanticensis 61 (2014), s. 301-323; tenże, Biblia i metafizyka: ku tomizmowi biblijnemu, w: Tomasz z Akwinu, Wykład Listu do Kolosan, Super Epistolam B. Pauli ad Colossenses lectura, Torun 2012, s. 9-21; M. Levering, Scripture and Metaphysics. Aquinas and the Renewal of Trinitarian Theology, Oxford 2004. 
przekazów i ich przyjmowaniu przez ich adresatów. To dlatego między innymi o wiele ważniejszy w procesie prorokowania jest poprawny sąd o rzeczach, a nie tyle kwestia takich czy innych obrazów pojawiających się w trakcie prorokowania. One, choćby nie wiadomo jak „cudowne” i nadzwyczajne są jedynie środkiem do przekazania poszczególnych, ważnych dla odbiorców treści (to samo dotyczy cudownego przewidywania przyszłych zdarzeń - nie chodzi o to, a o to, by określony przekaz trafił do tych ludzi, do których jest adresowany). W ten sposób „widzący” w taki czy w inny, całkiem spektakularny czy całkiem zwyczajny sposób może wypełnić powierzoną mu przez Boga misję. Współgra to z faktem, że tak czy inaczej, ciężar prawdziwości proroctwa i jego skuteczności zależy od samego Boga, ale bez pracy i uczestnictwa ludzkiego umysłu w zasadzie nie można mówić o prawdziwym proroctwie.

Oczywiście, to działanie Boga udoskonala proces intelektualny zachodzący w umyśle proroka, co wyraźnie zaznacza José María Arévalo już we wstępie do swojej książki, cytując Tomasza z Akwinu: „Miłość jest doskonałością woli, podczas gdy proroctwo jest doskonałością intelektu" ${ }^{11}$ ale, co także ważne, to nadprzyrodzone udoskonalenie nie niszczy ani nie pomniejsza tego, co zachodzi w naturalnym procesie ludzkiego myślenia. Wręcz przeciwnie, jest tego, co naturalne, uwzniośleniem i podkreśleniem. Pokazuje to także fakt dostrzeżony przez Akwinatę i jego XX-wiecznego interpretatora, że akt prorokowania jest procesem intelektualnym, a nie wolitywnym. Jest myśleniem, a nie tylko bezmyślnym przyjęciem i podaniem dalej. W ten sposób Arévalo krytycznie odnosi się do interpretacji tekstów Tomasza z Akwinu o proroctwie dokonywanej przez Kajetana, który akcentował właśnie rolę ludzkiej woli w procesie prorokowania ${ }^{12}$. W interpretacji kolumbijskiego autora voluntas humana jako ważny czynnik pojawia się dopiero po zasadniczym procesie prorokowania, który związany jest z pracą intelektu i dotyczy bardziej samego ogłoszenia woli czy planu Bożego niejako post factum, po tym, co już dokonało się w umyśle proroka.

Udoskonalenie ludzkiego umysłu poprzez łaskę Bożą w przebiegu prorokowania możemy dostrzec przede wszystkim w kwestii przedmiotu poznania jaki jest nam dany - jest nim, według kolumbijskiego teologa, koniec końców, sam Bóg jako „Byt nieskończony i najdoskonalszy, Źródło wszelkiej prawdy i doskonałości" ${ }^{13}$. Dlatego też, aby prorokować nie wystarczy być natchnionym

\footnotetext{
11 S. Th., II-II, q. 172, a. 2, ad 1.

12 Por. J.M. Arévalo, op. cit., s. 137-138.

13 J.M. Arévalo, op. cit., s. 161.
} 
przez Boga, nie tylko trzeba podlegać Jego działaniu, ale trzeba też odebrać Jego przesłanie, Jego Objawienie, jakąś prawdę o Nim, co podkreśla Arévalo w pierwszym rozdziale swej książki ${ }^{14}$. Dlatego w przypadku treści proroctwa nie są najważniejsze różne prawdy o rzeczach naturalnych w proroctwach się pojawiające, ale prawda o Bogu samym, jakaś jej część nam przez widzącego, a de facto, przez samego Boga odsłaniana. W sposób oczywisty prawda taka nie jest dostępna dla ludzkiego umysłu w sposób naturalny i możemy mieć w niej uczestnictwo dzięki Bożej inicjatywie uwznioślającej ludzki intelekt do poznania tego, co go przerasta ${ }^{15}$.

Objawiający się Bóg udoskonala umysł proroka na wszystkich etapach poznania, które w analizie Tomasza $\mathrm{z}$ Akwinu i jej interpretacji dokonanej przez Kolumbijczyka, są te same jak w przypadku naturalnego procesu poznawczego, co już zauważaliśmy na wstępie naszego przedłożenia. Dlatego, by dobrze przeanalizować proces poznawczy zachodzący w umyśle proroka, trzeba przyrównać go i badać podobnie jak się bada etapy zwyczajnego poznania ludzkiego. Stąd liczne odniesienia do epistemologicznych fragmentów doktryny Tomasza z Akwinu (Suma theologiae ${ }^{16}$ czy Suma Contra Gentiles ${ }^{17}$ czy De malo ${ }^{18}$ ) i Arystotelesa (De anima) opisujących proces poznawczy mający miejsce w umyśle człowieka ${ }^{19}$.

Pierwszym etapem procesu poznawczego proroka jest według klasycznej teorii Tomasza z Akwinu interpretowanej przez Arévalo acceptio specierum - odbiór form poznawczych przez intelekt możnościowy, co jest omówione w drugim rozdziale książki ${ }^{20}$. I co charakterystyczne, kolumbijski autor w nowatorski

14 Por. J.M. Arévalo, Rozdział 1. Noción general de la revelación, w: J.M. Arévalo, op. cit., s. 97-104.

15 Por. E. Alarcón, Aquinas' Harmonization of Evangelical Morality and Philosophical Ethics, w: Towards A Biblical Thomism. Thomas Aquinas and the Renewal of Biblical Theology, ed. P. Roszak i J. Vijgen, Pamplona 2018, s. 155-166.

16 Por. np. J.M. Arévalo, op. cit., s. 130 - S. Th., I, q. 12, a. 11, ad 3; S. Th., I, q. 14, a. 6; S. Th., I, q. 88, a. 3, ad 1.

17 Por. np. J.M. Arévalo, op. cit., s. 123 - Contra Gentiles, lib. III, cap. 154.

18 Por. np. J.M. Arévalo, op. cit., s. 109 - De malo, q. 16, a. 12, corp.

19 Por. J. Vijgen, The use of Aristotle in Aquinas's biblical commentaries, w: Reading Sacred Scripture with Thomas Aquinas. Hermeneutical Tools, Theological Questions and New Perspectives, ed. P. Roszak i J. Vijgen, Turnhout 2015, s. 287-346.

20 Por. J.M. Arévalo, Rozdział 2. La profecía: carisma de conocimiento, w: J.M. Arévalo, op. cit., s. 105-118. 
sposób odnosi ten Tomaszowy termin do kwestii prorokowania, gdyż normalnie Akwinata używał go do opisu początku procesu poznawczego związanego z odebraniem danych dostarczonych nam przez zmysły, co pokazuje na przykład cytat $\mathrm{z}$ komentarza do arystotelesowskiego De sensu et sensato: Quare homo autem non possit intelligere sine phantasmate, de facili potest assignari ratio quantum ad primam acceptionem specierum intelligibilium, quae a phantasmatibus abstrahuntur secundum doctrinam Aristotelis in tertio de anima ${ }^{21}$. Arévalo świadomie wprowadzając ten termin do zagadnienia proroctwa wskazuje, że nawet w przypadku omawiania poznania treści nadprzyrodzonych staje na stanowisku realizmu poznawczego (choć w przypadku proroctwa brzmi to paradoksalnie) prezentowanego $\mathrm{w}$ tradycji ludzkiej myśli przez Stagirytę i Tomasza z Akwinu, odrzucając przy tym platoński idealizm poznawczy ${ }^{22}$. Rzecz jasna, w przypadku proroctwa przyjmowane nie są dane dostarczane przez zmysły, jak w przypadku poznania rzeczywistości naturalnych, a dane dostarczane przez działanie objawiającego je Boga. Na taką możliwość interpretacji wskazuje zresztą sam Akwinata w dalszym tekście pochodzącym z drugiego traktatu Sentencia libri De sensu et sensato, kiedy to mawia zagadnienie ludzkiej wyobraźni: Sed experimento patet quod etiam ille qui iam acquisivit scientiam intelligibilem per species intellectas, non potest actu considerare illud cuius scientiam habet nisi occurrat ei aliquod phantasma ${ }^{23}$. Dalsza część traktatu Tomaszowego, która przyrównuje trwanie form poznawczych w intelekcie możnościowym do oddziaływania ciał oświecających na powietrze także wydaje się wskazywać na poprawność interpretacji Arévalo włączającego acceptio specierum do procesu prorokowania. Posset autem adhuc aliquis dicere quod species intelligibiles non manent in intellectu possibili humano, nisi quamdiu actu intelligit; postquam autem desiit actu intelligere pereunt et cessant species intelligibiles esse in intellectu per modum quo cessat lumen esse in aere apud absentiam corporis illuminantis: et ideo est necesse, si intellectus velit de novo intelligere, quod iterum se convertat ad phantasmata, ut acquirat species intelligibiles ${ }^{24}$. W każdym jednak przypadku czy odbierania danych ze

21 Sentencia libri De sensu et sensato, tr. 2, 1. 2, n. 4.

22 To z kolei pokazuje użycie tego terminu przez Tomasza z Akwinu w komentarzu do De Anima Arystotelesa: „Contra. Hoc non potest esse. Plato enim ponit, et opinatus est, quod intelligere non fiat per acceptionem specierum in intellectu, sed quod intellectus intelligat per quemdam contactum, inquantum scilicet occurrit et obviat speciebus intelligibilibus; et istum contactum attribuit circulo, sicut supra dictum est" - Sentencia libri De anima, lib. 1, 1. 8, n. 7 .

23 Sentencia libri De sensu et sensato, tr. 2, 1. 2, n. 4.

24 Ibidem, n. 5 . 
zmysłów czy z Objawienia Bożego, mowa jest o poznawaniu przedmiotów zewnętrznych w stosunku do ludzkiego umysłu, przy czym sam ten odbiór danych jest związany z działaniem ludzkiego intelektu (species intelligibiles non manent in intellectu possibili humano, nisi quamdiu actu intelligit), a więc mamy do czynienia ze współdziałaniem człowieka już na wczesnym etapie prorokowania.

Udoskonalające działanie Boga, konieczne jest także na drugim etapie prorokowania, według interpretującego myśl Akwinaty ojca Arévalo. Jest nim podejmowanie sądów o rzeczywistościach przyjętych przez intelekt możnościowy - iudicum de acceptis. Trzeci rozdział książki jest poświęcony właśnie temu specyficznemu dla ludzkiego poznania procesowi najważniejszemu dla całego prorokowania ${ }^{25}$. Tylko bowiem prawdziwi prorocy dzięki działaniu światła Bożego (lumen propheticum) w ich umyśle mogą właściwie rozumieć i sądzić rzeczywistości objawione, co ważne, $z$ pewnością i bezpieczeństwem ${ }^{26}$. W analizie tego etapu prorokowania jest czymś bardzo charakterystycznym, że Arévalo uważa intelekt możnościowy jako jedyny gotowy do przyjęcia doskonalącego działania Boga (poprzez swą potentia obedentialis). W ten sposób, w przeciwieństwie do poznania rzeczywistości naturalnych, w poznaniu rzeczywistości nadprzyrodzonych intelekt możnościowy ma większe znaczenie, ponieważ może być oświecony przez działanie samego Boga a nie poprzez działający w normalnym poznaniu własny, ludzki intelekt czynny ${ }^{27}$. Jak zaznacza to wyraźnie kolumbijski autor, cytując

25 J.M. Arévalo, Rozdział 3. El juicio profético, su naturaleza y su importancia en la revelación, w: J.M. Arévalo, op. cit., s. 119-142.

26 Por. J.M. Arévalo, op. cit., s. 123. Por. także: Contra Gentiles, lib. III, cap. 154: “Quae quidem revelatio fit quodam interiori et intelligibili lumine mentem elevante ad percipiendum ea ad quae per lumen naturale intellectus pertingere non potest. Sicut enim per lumen naturale intellectus redditur certus de his quae lumine illo cognoscit, ut de primis principiis; ita et de his quae supernaturali lumine apprehendit, certitudinem habet. Haec autem certitudo necessaria est ad hoc quod aliis proponi possint ea quae divina revelatione percipiuntur: non enim cum securitate aliis proferimus de quibus certitudinem non habemus. Cum praedicto autem lumine mentem interius illustrante, adsunt aliquando in divina revelatione aliqua exteriora vel interiora cognitionis auxilia: utpote aliquis sermo, vel exterius sensibiliter auditus, qui divina virtute formetur; aut etiam interius per imaginationem, Deo faciente, perceptus; sive etiam aliqua corporaliter visa exterius a Deo formata, vel etiam interius in imaginatione descripta; ex quibus homo, per lumen interius menti impressum, cognitionem accipit divinorum. Unde huiusmodi auxilia sine interiori lumine ad cognitionem divinorum non sufficiunt: lumen autem interius sufficit sine istis".

27 Por. J.M. Arévalo, op. cit., s. 109. O. Arévalo odnosi się do nauczania Akwinaty o poznaniu ludzkim w De mało wskazując na możliwość takiego poznania poprzez lumen 
Tomasza z Akwinu: Sicut enim in cognitione naturali intellectus possibilis patitur ex lumine intellectus agentis, ita etiam in cognitione prophetica intellectus humanus patitur ex illustratione divini luminis ${ }^{28}$. To dlatego też Arévalo za Akwinatą zaznacza, że proroctwo nie może być rodzajem stałej sprawności (habitus) człowieka ${ }^{29}$, ale jest związane z określonym czasowo oddziaływaniem światła prorockiego na niego. Relinquitur ergo quod lumen propheticum insit animae prophetae per modum cuiusdam passionis vel impressionis transeuntis ${ }^{30}$. Sam Akwinata wskazuje w tym fragmencie na najbardziej znane przykłady biblijne postaci proroków takich, jak Izajasz, Elizeusz, Eliasz czy Micheasz, cytując odpowiednie fragmenty Pisma Świętego ${ }^{31}$. Jeśli ciężar oddziaływania Bożego dotyczy intelektu możnościowego, to co z intelektem czynnym? Tu Arévalo w przeciwieństwo do wielu interpretatorów myśli Akwinaty pokazuje, że działa on normalnie, w sposób naturalny, po ludzku, pomimo tego, że prorok doświadcza potężnego działania Bożego światła. Kolumbijski autor uzasadnia to dogłębnie, odnosząc się do Pisma Świętego (wskazując między innymi na ludzkie wątpliwości proroka Samuela przy namaszczeniu Dawida na króla ${ }^{32}$ ) i na teksty Akwinaty dotyczące natury działania intelektu czynnego w umyśle ludzkim. W ten sposób prorokowanie będące doświadczeniem

intelligible dla intelektu ludzkiego - por. De malo, q. 16, a. 12, corp."Est autem considerandum, quod intellectualis hominum operatio secundum duo perficitur; scilicet secundum lumen intelligibile, et secundum species intelligibiles; ita tamen quod secundum species fit apprehensio rerum; secundum lumen intelligibile perficitur iudicium de apprehensis".

${ }^{28}$ S. Th., II-II, q. 171, a. 2, ad 1.

${ }^{29}$ Por. J.M. Arévalo, op. cit., s. 95. Tomasz z Akwinu w tym miejscu odchodzi od arystotelesowskiego podziału na rzeczy, które istnieją w duszy jako przynależące do potencjalności, uczucia i sprawności, przy czym zaznacza, że w jakiś sposób można zaliczyć proroctwo do passiones, gdyż polega na doznawaniu. Tak zresztą myślało wielu starożytnych. Oczywiście Arystoteles nie mógł znać światła łaski objawionej przez Jezusa Chrystusa - "illa divisio philosophi non comprehendit absolute omnia quae sunt in anima, sed ea quae possunt esse principia moralium actuum, qui quandoque fiunt ex passione, quandoque autem ex habitu, quandoque autem ex potentia nuda, ut patet in his qui ex iudicio rationis aliquid operantur antequam habeant habitum. Potest tamen prophetia ad passionem reduci, si tamen nomen passionis pro qualibet receptione accipiatur; prout philosophus dicit, in III de anima, quod intelligere pati quoddam est" - S. Th., II-II, q. 171, a. 2, ad 1.

${ }^{30}$ S. Th., II-II, q. 171, a. 2, corp.

31 Por. S. Th., II-II, q. 171, a. 2, corp. P. Roszak, The Place and Function of Biblical Citations in Thomas Aquinas's Exegesis, w: Reading Sacred Scripture with Thomas Aquinas. Hermeneutical Tools, Theological Questions and New Perspectives, ed. P. Roszak i J. Vijgen, Turnhout 2015, s. 115-139.

32 Por. J.M. Arévalo, op. cit., s. 146-147. 
działającego Boga, w rozumieniu Arévalo, zarazem pozostaje czymś „głęboko ludzkim" (profundamente humana), jak to opisuje we wstępie do książki Germán Correa Miranda ${ }^{33}$.

W swej książce kolumbijski autor w krótki sposób odrzuca za Tomaszem z Akwinu możliwość zaistnienia „proroctwa naturalnego” czy „świeckiego”, zaznaczając przy tym, że nie stanowi ono przedmiotu jego studium. Jest to poprawny osąd, gdyż fenomen „naturalnego proroctwa”, który był opisywany przez wczesnośredniowieczną filozofię arabską i żydowską, przynależy bardziej do zjawisk społecznych i politycznych analizowanych przez filozofię polityczną, a nie jest właściwym przedmiotem badań teologicznych ${ }^{34}$. Ponadto będąc pokłosiem awerroistycznych interpretacji Arystotelesa, koncept „proroków świeckich” w pewien sposób współgra $\mathrm{z}$ charakterystycznym dla tych prądów uderzeniem w możliwości działania indywidualnego umysłu ludzkiego, co stoi w oczywisty sposób w sprzeczności z przesłaniem Tomasza z Akwinu, broniącego, jak wyżej mogliśmy zobaczyć naturalnej sprawczości ludzkiego intelektu ${ }^{35}$ nawet w przypadku prawdziwego proroctwa i rzeczywistego działania Bożej łaski. Ten kierunek właśnie podejmuje ojciec Arévalo w swych rozważaniach. Nawet w przypadku analizy jednej z największych Bożych nadprzyrodzonych interwencji w świat naturalny, jakimi są adresowanie nadprzyrodzonej wiedzy do umysłu ludzkiego, okazuje się, że umysł ludzki działa w sposób autonomiczny i wolny i w ten sposób swymi naturalnymi siłami może kooperować w umyśle proroka ze światłem Bożej łaski i zostać przezeń wywyższony ${ }^{36}$. Paradoksalnie, najwyraźniej może da się to zaobserwować, jak czyni do kolumbijski dominikanin, na przykładzie ludzi, którzy nie będąc prorokami, ogłaszali jakąś prawdę Bożą - w ten sposób Kajfasz przepowiedział charakter zbawczy śmierci Jezusa

33 G. Correa Miranda, op. cit., s. 33.

34 Por. A. Machowski, La pleamar de las profecías fue rechazada ya en el siglo XIII. La autonomía de lo político en relación con el pensamiento teológico de los textos de Tomás de Aquino sobre la profecía, w: De natura. La naturaleza en la Edad Media, pod red. J. L. Fuertes Herreros i A. Poncela González, Ribeirao 2015, s. 587-595; A. Machowski, "Ut omnes aliquam partem habeant in principatu”. Uczestnictwo obywateli w życiu politycznym wspólnoty w myśli Tomasza z Akwinu, Toruń 2021, s. 96-99.

35 Por. De unitate intellectus.

36 M. Mróz, Virtue Epistemology and Aquinas's Biblical Commentary on the Corpus Paulinum, w: Reading Sacred Scripture with Thomas Aquinas. Hermeneutical Tools, Theological Questions and New Perspectives, ed. P. Roszak i J. Vijgen, Turnhout 2015, s. 435-456. 
Chrystusa, choć tak naprawdę nie wiedział, co przekazuje, nie miał właściwego sądu o przekazywanej treści, nie poznał jej i dlatego nie był prorokiem ${ }^{37}$.

Powracając do krótko traktowanego przez ojca Arévalo tematu „naturalnego proroctwa”, jest ono niezgodne z tym, co już zaznaczaliśmy na wstępie proroctwo służy do objawiania prawdy Bożej, prawdy o Bogu, a rzeczywistości naturalne mamy poznawać swymi naturalnymi siłami, jak pokazuje to Tomasz z Akwinu, odrzucając prawdziwość „świeckich proroctw”. Dlatego też znacznie więcej uwagi i ostatnią, czwartą część swojej książki Kolumbijczyk poświęca innemu ograniczeniu funkcjonowania prawdziwych proroctw - mianowicie potrzebujemy ich jedynie tu na ziemi, podczas gdy w niebie błogosławieni dysponować będą innego rodzaju doskonalszym poznaniem - visio beatifica ${ }^{38}$.

Wartość omawianego przez nas dzieła podnosi fakt, że na końcu książki w formie apendyksu załączony jest reedytowany artykuł ojca José María Arévalo dedykowany obronie ojca José María Lagrange, założyciela Szkoły Biblijnej $\mathrm{w}$ Jerozolimie ${ }^{39}$. Wiąże się on z głównym przesłaniem książki o proroctwie jakim, moim zdaniem, jest ukazanie w działaniu prorockim współdziałania Bożej łaski i natury człowieka, bowiem o. Lagrange podkreślał rolę natury ludzkiej w procesie tworzenia tekstu biblijnego w żywej przed laty dyskusji prowadzonej z modernistami i fideistami. Obrona naturalnego wymiaru boskiego przesłania i właściwe ukazywanie go jest de facto jedynym sposobem by uniknąć fałszywego racjonalizmu czy błędnego fideizmu. Lagrange w swoim nauczaniu wskazywał na to, że Bóg realizując swoje plany i adresując do nas swoje Słowo, używa ludzkich środków i ludzkiego pośrednictwa. Treść dołączonego artykułu współgra więc $\mathrm{z}$ analizą fenomenu proroctwa dokonaną przez tego samego autora. Równie cennym dodatkiem i wprowadzeniem nas w nauczanie o. Arévalo jest otwierający publikacje wstęp autorstwa José Gabriela Mesa Angulo przedstawiający krótką sylwetkę naukową autora książki ${ }^{40}$.

W efekcie otrzymaliśmy bardzo udaną analizę ciekawego problemu epistemologicznego, jakim jest zjawisko proroctwa. Dogłębne badanie pozwala na

37 Por. J.M. Arévalo, op. cit., s. 112-113 i 122. Autor odwołuje się tu do Komentarza Tomasza z Akwinu do Ewangelii św. Jana - por. In Joannem, cap. XI, lect. 7.

38 Por. J.M. Arévalo, Rozdział 4. Deficiencia e imperfección de la profecía. La limitación del conocimiento profético, w: J.M. Arévalo, op. cit., s. 143-162.

39 Por. J.M. Arévalo, El padre José María Lagrange, O.P. i el Modernismo, w: J.M. Arévalo, op. cit., s. 169-175.

40 Por. J.G. Mesa Angulo, Prólogo. Un tesoro revelado, w: J.M. Arévalo, op. cit., s. 7-13. 
nowo odkryć słynne adagium Tomaszowe gratia non tollit naturam sed perficit. Okazuje się, że Bóg w swym działaniu i przesłaniu odwołuje się do naturalnych zdolności ludzkich i chce się nimi posłużyć wzywając nas do owocnego współdziałania. Przypomnienie pracy o. Arévalo jest szczególnie przydatne dzisiaj, w obecnych uwarunkowaniach kulturowych, kiedy to w naszych społecznościach doświadczamy głębokiego kryzysu racjonalności i religijności. Postmodernizm wydaje się nie mieć na to odpowiedzi, dlatego może warto powrócić do klasycznego sposobu uprawiania filozofii i teologii i tam szukać możliwych odniesień i lekarstw na choroby współczesności, stąd warto sięgnąć po książkę o. José María Arévalo. Wszak, jak napisał we wstępie o. Germán Correa: „wraz z postmodernizmem nie przezwyciężyliśmy modernizmu, a wręcz przeciwnie, $\mathrm{w}$ wielu aspektach religijnych na nowo w nim się pogrążyliśmy"41.

\section{Bibliografia}

Alarcón E., Aquinas' Harmonization of Evangelical Morality and Philosophical Ethics, w: Towards A Biblical Thomism. Thomas Aquinas and the Renewal of Biblical Theology, eds. P. Roszak i J. Vijgen, Pamplona 2018, s. 153-172.

Arévalo J.M., El padre José María Lagrange, O.P. y el Modernismo, w: J.M. Arévalo, El proceso intelectual de la profecía según Santo Tomás, Bogota 2020, s. 169-175.

Arévalo J.M., El proceso intelectual de la profecía según Santo Tomás, Bogota 2020.

Correa Miranda G., Liminar. Los juicios de Dios en la mente de un profeta, w: J.M. Arévalo, El proceso intelectual de la profecía según Santo Tomás, Bogota 2020, s. 15-88.

Levering M., Scripture and Metaphysics. Aquinas and the Renewal of Trinitarian Theology, Oxford 2004.

Machowski A., La pleamar de las profecías fue rechazada ya en el siglo XIII. La autonomía de lo político en relación con el pensamiento teológico de los textos de Tomás de Aquino sobre la profecía, w: De natura. La naturaleza en la Edad Media, ed. J.L. Fuertes Herreros, A. Poncela González, Ribeirao 2015, s. 587-595.

Machowski A., "Ut omnes aliquam partem habeant in principatu". Uczestnictwo obywateli w życiu politycznym wspólnoty w myśli Tomasza z Akwinu, Toruń 2021.

Marcos, A., Perez Marcos, M., Caverna 2.0. Las raíces dualistas del transhumanismo, Scientia et Fides 2 (2019), s. 23-40 (DOI: http://dx.doi.org/10.12775/SetF.2019.014).

Merlo, J., Zarathustra and Transhumanism: Man is Something to Be Overcome, Scientia et Fides, 2 (2019), s. 41-61 (DOI: http://dx.doi.org/10.12775/SetF.2019.015).

41 Por. G. Correa Miranda, op. cit., s. 21. 
Mesa Angulo J.G., Prólogo. Un tesoro revelado, w: J.M. Arévalo, El proceso intelectual de la profecía según Santo Tomás, Bogota 2020, s. 7-13.

Mróz M., Virtue Epistemology and Aquinas's Biblical Commentary on the Corpus Paulinum, w: Reading Sacred Scripture with Thomas Aquinas. Hermeneutical Tools, Theological Questions and New Perspectives, ed. P. Roszak i J. Vijgen, Turnhout 2015, s. 435-456.

Roszak P., Biblia i metafizyka: ku tomizmowi biblijnemu, w: Tomasz z Akwinu, Wykład Listu do Kolosan, Super Epistolam B. Pauli ad Colossenses lectura, Toruń 2012, s. 9-21.

Roszak P., Exégesis y metafísica. En torno a la hermenéutica bíblica de Tomás de Aquino, Salmanticensis 61 (2014), s. 301-323.

Roszak P., The Place and Function of Biblical Citations in Thomas Aquinas's Exegesis, w: Reading Sacred Scripture with Thomas Aquinas. Hermeneutical Tools, Theological Questions and New Perspectives, ed. P. Roszak i J. Vijgen, Turnhout 2015, s. 115-139.

Reading Sacred Scripture with Thomas Aquinas. Hermeneutical Tools, Theological Questions and New Perspectives, eds. P. Roszak i J. Vijgen, Turnhout 2015.

Tomasz z Akwinu, De malo, Questiones disputate, Turyn 1942.

Tomasz z Akwinu, De unitate intellectus contra Averroistas, Rzym 1976.

Tomasz z Akwinu, De veritate, Questiones disputate, Turyn 1942.

Tomasz z Akwinu, In Aristotelis librum De anima comentarium, Turyn 1936.

Tomasz z Akwinu, In Isaiam prophetam expositio, Paryż 1876.

Tomasz z Akwinu, In Evangelium Secundum Joannem, Turyn 1926.

Tomasz z Akwinu, In omnes S. Pauli apostoli Epistolas commentaria, Turyn 1929.

Tomasz z Akwinu, Sentencia libri De sensu et sensato cuius secundus tractatus est De memoria et reminiscencia, Paryż-Rzym 1984.

Tomasz z Akwinu, Summa contra gentiles, Rzym 1934.

Tomasz z Akwinu, Summa Theologica, Paryż 1934.

Tomasz z Akwinu, Wykład Listu do Kolosan, Super Epistolam B. Pauli ad Colossenses lectura, Toruń 2012.

Vijgen J., The use of Aristotle in Aquinas's biblical commentaries, w: Reading Sacred Scripture with Thomas Aquinas. Hermeneutical Tools, Theological Questions and New Perspectives, eds. P. Roszak i J. Vijgen, Turnhout 2015, s. 287-346. 